\title{
A CONFORMAÇÃO NEOLIBERAL DAS POLÍTICAS EDUCACIONAIS DE ENSINO SUPERIOR NO GOVERNO LULA
}

\author{
LA CONFORMACIÓN NEOLIBERAL DE LAS POLÍTICAS DE EDUCACIÓN SUPERIOR \\ EN LA ADMINISTRACIÓN DE LULA
}

\section{THE NEOLIBERAL CONFORMATION OF HIGHER EDUCATION POLICIES IN LULA'S ADMINISTRATION}

DOI: http://dx.doi.org/10.9771/gmed.v11i2.32473

\author{
Gabriel Teles ${ }^{1}$
}

\begin{abstract}
Resumo: O presente artigo tem por objetivo analisar e reconstituir as políticas educacionais de ensino superior no governo Lula (2003-2010). Nesse sentido, buscamos explicitar a conformação neoliberal em que o ensino superior público passou ao longo desse governo em continuidade aos governos passados. O método de investigação utilizado é o método dialético que, à luz dos conceitos e categorias marxistas, nos auxiliará a analisar a dinâmica da luta de classes no Brasil, focalizando a disputa entre as frações da classe dominante e sua relação com a burocracia governamental ao longo do governo petista.
\end{abstract}

Palavras-chaves: Governo Lula. Ensino Superior. Neoliberalismo.

Resumen: Este artículo tiene como objetivo analizar y reconstruir las políticas educativas de la educación superior en el gobierno de Lula (2003-2010). En este sentido, buscamos aclarar la conformación neoliberal en la cual la educación superior pública pasó a lo largo de este gobierno en continuidad con gobiernos anteriores. El método de investigación utilizado es el método dialéctico que, a la luz de los conceptos y categorías marxistas, nos ayudará a analizar la dinámica de la lucha de clases en Brasil, centrándose en la disputa entre las fracciones de la clase dominante y su relación con la burocracia del gobierno en todo momento. del gobierno petista.

Palabras clave: Gobierno de Lula. Enseñanza superior. Neoliberalismo.

Abstract. This article aims to analyze and reconstruct the educational policies of higher education in the Lula government (2003-2010). In this sense, we seek to clarify the neoliberal conformation in which public higher education passed throughout this government in continuity with past governments. The research method used is the dialectical method which, in the light of Marxist concepts and categories, will help us to analyze the dynamics of class struggle in Brazil, focusing on the dispute between the fractions of the ruling class and their relationship with the government bureaucracy throughout. of the petista government.

Keywords: Lula Government. Higher education. Neoliberalism.

\section{Introdução}

A análise do governo Lula obedece a um conjunto de interpretações diversas que se digladiam com objetivo de explicar e compreender o seu significado e suas consequências para a dinâmica dos conflitos da sociedade brasileira. Nesse sentido, de modo à contribuir ao debate, o presente texto busca reconstituir, criticamente, as políticas educacionais durante este governo, compreendidos nos anos iniciase em 2003 e vai até final de 2010. 
O itinerário de nossa análise será a explicitação da continuidade, especialmente no ensino superior, da dimensão neoliberal na área educacional, que estava sendo implementada nos governos anteriores, especialmente de Fernando Henrique Cardoso. O método de investigação utilizado é o método dialético que, à luz dos conceitos e categorias marxistas, nos auxiliará a analisar a dinâmica da luta de classes no Brasil, focalizando a disputa entre as frações da classe dominante e sua relação com a burocracia governamental ao longo do governo petista. Por esse ângulo, apresentaremos uma breve análise do governo Lula em sua dimensão ampla para posteriormente focalizar as medidas na área de educação.

\section{O neoliberalismo neopopulista do governo Lula}

Após três tentativas consecutivas de pleitear a vitória nas eleições para presidente da República (1989, 1994 e 1998), Luís Inácio Lula da Silva, do Partido dos Trabalhadores (PT), é finalmente eleito em 2002, em segundo turno, contra José Serra, do Partido da Social Democracia Brasileira (PSDB), expresidente da UNE em 1964. A vitória do Partido dos Trabalhadores suscitou, inicialmente, grandes esperanças, sobretudo para o bloco progressista, que desde a redemocratização do país esteve na oposição à nível federal. O PT, forjado no novo sindicalismo, oriundo das greves do ABC Paulista no fim da Ditadura Militar, em conjunto com as entidades de base da Igreja e uma enorme diversidade de movimentos sociais, finalmente chega ao poder. No entanto, o PT que consegue a vitória eleitoral não é o mesmo partido político da década de 1980, que aglutinava várias perspectivas políticas à esquerda, cuja hegemonia se dava no grupo dirigido por Lula, aos moldes da socialdemocracia clássica mundial.

O desenvolvimento histórico e organizativo do Partido dos Trabalhadores representa, de sua fundação até a vitória nas eleições de 2002, um conjunto de metamorfoses importantes. Assim, paulatinamente, esse partido vai crescendo, vencendo eleições municipais, estaduais, representando mais cargos e menos radicalidade, expulsando ou deixando sair ${ }^{2}$ aqueles que não concordam com a hegemonia das diretrizes dessa organização. Por esse ângulo, a vitória nas eleições presidenciais de 2002 não foi fruto de mero ocaso ou eventos aleatórios:

[...] o PT já vinha se preparando profissionalmente para a campanha de 2002. Para tanto, amealhou recursos consideráveis por meio do financiamento de campanhas e abrandou seu discurso político, processo que já vinha em curso desde 1994, mas que, em 2002, alcançaria um novo estágio com a Carta aos Brasileiros (FERREIRA, 2011, p. 101, grifos nosso).

A Carta ao Povo Brasileiro é sintomática da consequência dessa mudança que já vinha sendo desenvolvida desde o início pelo grupo dominante no interior do partido ${ }^{3}$. Nela, é colocada que os acordos estabelecidos pelo ex-presidente Fernando Henrique Cardoso, responsável pela consolidação e cristalização do neoliberalismo no país, seriam honradas. Assim, Lula assinala o não rompimento com as demandas impostas para os países de capitalismo subordinado, cumprindo à risca a cartilha emitida pelos órgãos internacionais (Banco Mundial, Fundo Monetário Internacional, etc.): "Vamos preservar o superávit primário o quanto for necessário para impedir que a dívida interna aumente e destrua a 
confiança na capacidade do governo de honrar os seus compromissos" (PARTIDO DOS TRABALHADORES, 2002, p. 91).

Desse modo, a vitória de Lula não representou uma oposição ao reordenamento neoliberal colocado pelos governos passados desde 19894. Trata-se, na verdade, de um aprofundamento do neoliberalismo brasileiro, mas com algumas especificidades, graças a peculiar composição social e histórica do PT e sua ligação com os movimentos sociais, sindicatos, etc. É assim que surge, na interpretação de alguns marxistas, o neoliberalismo neopopulista, que irá ser a determinação fundamental das ações e políticas de Lula.

O neoliberalismo neopopulista brasileiro representa uma recomposição do bloco dominante ${ }^{5}$ a partir da maior força política oriunda do bloco progressista, o Partidos dos Trabalhadores e seus aliados.

Nesse sentido, certas frações da burocracia como classe social, no caso setores da burocracia partidária e da burocracia sindical, tornam-se parte do bloco dominante. No entanto, estes sofrem uma metamorfose e trocam sua concepção integracionista por uma neoliberal, mantendo um discurso e alguns elementos antigos de integracionismo. As políticas estatais possuem como determinação fundamental o processo de acumulação de capital e os interesses da classe capitalista, que coordena tal processo, mas existem variações na forma e implementação de tais políticas dependendo da composição do bloco dominante, de suas principais forças, da pressão popular, do conjunto dos interesses sociais, etc. (VIANA, 2015, p. 83).

Assim, neoliberalismo neopopulista se origina nas variações da implementação das medidas neoliberais. Coexistem, dessa maneira, medidas de estabilidade financeira e política, corte de gastos, privatizações, etc., com parciais gastos sociais, especialmente com setores mais pauperizados da população brasileira, tais como o lumpemproletariado, ao lado de políticas sociais paliativas ("microreformismos") e políticas segmentares visando a cooptação de setores dos grupos sociais, especialmente os organizados em movimentos sociais (mulheres, negros, estudantes, etc.). Passemos agora a exposição e análise de tais medidas e principais políticas do governo Lula.

Como já colocado anteriormente, o governo Lula estabelece, inicialmente, um processo de manutenção das medidas neoliberais de Fernando Henrique Cardoso. Segundo o cientista político Armando Boito Jr., esse processo é percebido já no primeiro ano do mandato do governo Lula:

O novo governo, de modo surpreendente para muitos observadores, não só está mantendo os pilares do modelo capitalista neoliberal dependente, como está aprofundando alguns de aspectos desse modelo. Os membros da equipe governamental não tocaram na herança neoliberal de FHC: a abertura comercial, a desregulamentação financeira, a privatização, o ajuste fiscal e o pagamento da dívida, a redução dos direitos sociais, a desregulamentação do mercado de trabalho e a desindexação dos salários. Em relação a esse último item verifica-se uma omissão particularmente grave: o governo Lula não fez e não disse nada até aqui sobre a desindexação dos salários imposta aos trabalhadores pelo neoliberalismo" (BOITO JR, 2003, p. 1).

A gestão petista, em seus primeiros meses, de acordo com Reis (2007, p. 523), “[...] se limitou a propor as reformas já enviadas à consideração do Congresso por FHC (reforma da previdência e tributária)". Progressivamente o governo Lula vai aprofundando o caráter neoliberal do Estado brasileiro a partir da submissão às diretrizes dos organismos multilaterais, culminando, por exemplo, na concessão de total autonomia formal ao Banco Central (BC) já em 2003, reordenando a política econômica à noção de 
credibilidade (COUTINHO, 2003). Aqui, a noção de credibilidade refere-se como um indicativo ao capital transnacional, apontando para a segurança financeira que as empresas dos países de capitalismo imperialista teriam no Brasil. Assim, o BC articula três elementos fundamentais para o aprofundamento do capital transacional no país: superávits primários, câmbio flutuante e juros elevados.

A crer nos documentos do Ministério da Fazenda, o Governo Lula acredita, piamente, na possibilidade de resolver os problemas da economia brasileira, em particular a vulnerabilidade externa e a fragilidade financeira do setor público, através do aprofundamento do ajuste fiscal, acompanhado pelas reformas previdenciária, trabalhista e tributária. E mais, a melhora conjuntural de alguns indicadores nos primeiros meses do Governo Lula seria a evidência de que a política adotada estaria no caminho correto. Acontece, contudo, que esse critério - baseado em indicadores extremamente voláteis e que expressam movimentos de curtíssimo prazo -, é altamente duvidoso quando se trata de se avaliar o sucesso de uma política econômica. $\mathrm{Na}$ realidade, a observação e análise da evolução das principais variáveis macroeconômicas indicam que a dinâmica da economia nos primeiros quinze meses do novo governo não mudou no essencial. Muito pelo contrário, os movimentos constatados foram bastante semelhantes aos observados durante a vigência dos Governos de FHC (FILGUEIRAS; PINTO, 2009, p. 253).

Além disso, um conjunto de medidas que corroeram os direitos dos trabalhadores, desagregação das cadeias produtivas e da deslocalização e reterritorialização dos ciclos dessas mesmas cadeias, reafirmando a posição do capitalismo brasileiro na divisão internacional do trabalho enquanto produtor de mercadorias de pouco valor agregado, intensa em força de trabalho, energia e recursos naturais (BARRETO; LEHER, 2008). Apesar da estratégia internacional do governo Lula (como por exemplo a criação do BRICS), ela não chegou perto de um rompimento com o seu caráter subordinado ante à exploração internacional dos países de capitalismo imperialista.

A renegociação da dívida foi convertida em um complexo processo que redefiniu a
força relativa das frações de classes no bloco de poder dos países latino-americanos, em
favor das frações locais mais internacionalizadas fortalecendo os setores pró-
imperialistas (financeiros, agronegócio, commodities). Assim, as condicionalidades
desses organismos (Banco Mundial e Fundo Monetário Internacional) não foram
apenas uma imposição de fora para dentro, mas medidas que, para determinadas
frações, seriam extremamente benéficas e lucrativas. Com efeito, o ajuste estrutural
delineado pelo FMI e pelo BM e, mais tarde, pelo Plano Brady exigiu simultaneamente
uma busca incessante de divisas provenientes de exportações - conforme o BM, os
nichos de mercado mais promissores são o agronegócio e a manufatura de produtos
extraídos da natureza (commodities) (LEHER, 2007, p.10).

Até mesmo o PAC, Programa de Aceleração do Crescimento, criado em 2006 e implementado no início segundo mandato do Governo Lula, que se apresentava como uma medida pautada na defesa do desenvolvimento nacional, compreendido como um elemento fundamental para a autonomia dos estados nacionais, significou, em verdade, um aprofundamento da subordinação ao capital transnacional. Ela expressa a necessidade da estabilidade econômica e o cumprimento de acordos internacionais. O PAC se apropria indiretamente de determinados recursos do Estado que seriam destinados às políticas sociais e contribui para a manutenção das medidas neoliberais no país, priorizando o pagamento dos serviços da dívida (juros e amortização), como demonstra o estudo de Rodrigues e Salvador (2011). Priorizando o 
investimento em setores primários da economia, especialmente o energético (petróleo, etc.), o governo Lula contribuiu para o processo de

[...] reprimarização das exportações nas economias periféricas e no círculo vicioso da especialização retrógrada que afeta as indústrias e as economias. Aliada às medidas de liberalização financeira, ao acelerado processo de desnacionalização dos parques produtivos e à limitada autonomia na estratégica área de geração de conhecimentos científicos e tecnológicos, a dependência dos países periféricos é reproduzida, aprofundando a inserção subordinada na divisão internacional do trabalho. [...] Ao mesmo tempo em que esse novo padrão de especialização produtiva multiplica o volume de exportações, os salários e as condições gerais de trabalho e de vida da maioria da população denotam uma precarização crescente (CHAGAS; CARVALHO; MARQUESAN, 2015, p.284, negritos nosso).

Em contornos gerais, estas são algumas medidas colocadas pelo governo Lula ao longo de seus mandatos $^{6}$. Trata-se de uma continuidade dos governos antecessores que emergiram após a redemocratização do país. No entanto, há algumas particularidades que dão sentido ao termo "neopopulista" do neoliberalismo neopopulista dos governos petistas.

[...] o neoliberalismo sob o governo petista assume outras formas. Ele dedica certa energia e recursos a setores específicos da sociedade. As burocracias das centrais sindicais, setores da classe intelectual universitária e dos institutos federais, burocracia dos movimentos sociais e entidades estudantis conformam uma base social cristalizada do governo. Outra estratégia do governo petista é criar políticas segmentares, cooptando determinados grupos sociais. Por fim, o governo empreende um processo de ampliação de políticas microassistencialistas que atendem muito precariamente parcelas do lumpemproletariado. Essas políticas neopopulistas e outras criam uma base social eleitoral para o partido durante certo período de tempo, mas não resolvem os problemas sociais (MAIA, 2016, p. 58).

Nesta citação, Maia se refere a algumas medidas colocadas pelo Governo Lula que lhe deram uma ampla sustentação e base para vencer as eleições e aglutinar diversos setores na defesa do governo. Rapidamente, colocaremos algumas dessas medidas que trazem consequências para a dinâmica da luta de classes no contexto brasileiro. Afinal, se o proletariado e demais classes desprivilegiadas, além dos movimentos sociais e setores da sociedade civil organizada, resistiam às medidas neoliberais de Collor e FHC, no Governo Lula, muito desses movimentos, especialmente aqueles ligados historicamente ao PT e seus aliados, irão se silenciar ou contribuir para o amortecimento dos conflitos sociais no interior dessa nova fase do neoliberalismo no país.

Os iniciais gastos sociais do governo Lula centraram-se em algumas diretrizes já colocadas em seu programa político das eleições de 2002. É assim que surge o Fome Zero, primeira política estatal da era petista que durou pouco tempo, sendo substituída, posteriormente, pelo ainda vigente Bolsa Família. O bolsa família, antes de ser uma criação do governo Lula, significou a unificação de um conjunto de programas de transferência de renda em nível municipal, estadual e federal desde 1995 que já existia, ainda de forma rudimentar, no governo FHC. No entanto, o bolsa família não nasce nas políticas estatais brasileira - não a sua ideia e diretrizes básicas.

Trata-se, fundamentalmente, do desenvolvimento das recomendações do Banco Mundial que já apontava a necessidade de políticas estatais de transferência de renda (MAGNOLI, 2014). É o microreformismo, que visa ofuscar a necessidade de reformas estruturais e estabelecer políticas paliativas, 
que apenas amenizam superficialmente os graves problemas sociais gerados pelo capitalismo contemporâneo. Assim, o programa Bolsa Família, de acordo com Magnoli (2014), tornou-se uma importante arma político-eleitoral do governo petista, impulsionando um suposto "consumo popular", lhe dando margens para o congelamento de debates políticos mais amplos em voga na época, tal como a agenda de reformas na educação, saúde, etc.

Assim, o bolsa família, apesar de um programa que trouxe a possibilidade do consumo primário, especialmente para a população mais pauperizada, não tinha como meta a extinção do próprio processo de pauperização enquanto relação social.

O que o bolsa-família ensina para aqueles que ainda não se convenceram do acerto da Lei Geral da Acumulação Capitalista é bem simples: um programa federal de esmolas apenas favorece a manutenção da mesma estrutura produtiva cuja desigualdade social o programa de esmolas diz querer combater (LESSA, 2018, p. 03).

As políticas de transferência de renda serão uma das políticas que mais o governo se utilizará, tal como os mais diversos programas de crédito consignado ${ }^{7}$ e o Programa Universidade Para Todos (PROUNI) - iremos nos debruçar de forma mais detida, posteriormente, sobre o PROUNI no próximo tópico.

Uma outra modalidade de microreformismo e políticas paliativas são as políticas segmentares ${ }^{8}$ para determinados grupos e setores sociais, aprofundando o processo de cooptação dos movimentos sociais, especialmente lideranças/dirigentes de determinadas ramificações desses movimentos. Assim, no governo Lula são criadas diversas secretarias especiais que versam sobre os "problemas" de vários grupos sociais e segmentos da sociedade brasileira. A relação "harmônica" com determinadas ramificações de movimentos sociais se deu não apenas com aquelas nas quais o governos petista já possuía afinidade e articulação (aparelhamento) (MST, UNE, etc.) antes da chegada ao poder, mas ela foi ampliada à medida que eram alargadas as vantagens oferecidas para os dirigentes de organizações mobilizadoras em troca de favorecimentos, cargos, apoio governamental, etc. Assim, houve um processo de aparelhamento de diversas organizações mobilizadoras de movimentos sociais, organizações não-governamentais (ONGs), institutos, etc., que recrutavam e financiavam setores estratégicos da sociedade que forneciam uma base de apoio parcialmente sólida no interior de determinadas parcelas de grupos sociais.

O Movimento dos Trabalhadores Rurais Sem Terra (MST) é exemplar sobre essa relação, como bem coloca Pinassi (2009);

Uma das estratégias usadas nos parece particularmente problemática. E ela se refere, primeiro, aos laços que historicamente o PT estabeleceu com os movimentos sociais de massas, entre os quais se destaca o MST. E, de como, uma vez no poder, esses laços se convertem, positivamente, em benefícios concretos ao movimento, o que tem possibilitado, através da abertura de linhas crédito e estímulo à formação de cooperativas, por exemplo, condições de competitividade no mercado para os assentamentos já consolidados. Esses benefícios selam um comprometimento político que nos parece um ônus excessivamente grande para a necessária autonomia às estratégias de luta que o movimento deve preservar de qualquer maneira. [...] Nessa medida, ou o movimento continua acorrendo para as políticas públicas e abandona o confronto mais radical contra o capital deixando à deriva a maioria de sua militância acampada e precariamente assentada (PINASSI 2009, p. 8). 
Em síntese, há um intenso processo de aparelhamento, institucionalização, burocratização e mercantilização de determinados setores dos movimentos sociais. Analisemos, agora, as políticas educacionais ao longo desse período histórico.

\section{As politicas educacionais do Governo Lula}

Em linhas gerais, quanto às políticas educacionais do governo Lula, o receituário neoliberal se resguarda. Trata-se não só de uma continuidade do governo de Cardoso, mas de um aprofundamento e alargamento do entendimento da educação como mercancia9 ("mercadoria-educação").

Com o desmonte do Estado enquanto um dos propulsores diretos da acumulação de capital, diversos serviços sociais, tais como saúde, segurança, educação, etc., começam a despertar interesses de determinadas frações da burguesia com objetivos de apropriar mais-dinheiro de tais serviços que, enfim, estão livres para a iniciativa privada. Assim, o capital educacional no neoliberalismo, inicialmente de origem nacional e posteriormente internacional, começa a se expandir de forma exponencial e encontra no governo Lula o seu principal e maior crescimento.

Antes de entrarmos diretamente sobre as políticas educacionais, é necessário colocar a existente disputa entre as mais diversas forças políticas acerca do papel da educação e seus rumos na sociedade capitalista brasileira. Sem dúvidas, os órgãos internacionais do capitalismo imperialista e a burguesia nacional, bem como suas classes auxiliares, tomaram a dianteira desse processo e contribuíram com o governo para adotar diversas políticas atreladas aos interesses da classe dominante.

De Paula (2016) evidencia que diversos intelectuais que orientaram os caminhos da educação brasileira, no governo Lula, representam ou integram um movimento empresarial chamado Todos pela Educação (TPE), criado em 2005. Seus vínculos e diretrizes respondem diretamente as recomendações do Banco Mundial, Fundo Monetário Internacional, etc., sendo que, desde a década de 1990, esse grupo buscou direcionar a educação para a "[...] produção de uma nova sociabilidade mais adequada aos interesses privados do grande capital nacional e internacional” (SHIROMA; GARCIA; CAMPOS, 2011, p. 227).

Partiu da constatação de que as corporações estavam atuando em centenas de grandes projetos educacionais com objetivos educacionais pertinentes, afins aos interesses corporativos que os patrocinam, mas que a dispersão dos esforços impedia uma intervenção 'de classe' na educação pública, objetivo altamente estratégico, pois envolve a socialização de mais de 50 milhões de jovens, a base da força de trabalho dos próximos anos. Os setores dominantes, após a articulação política dos grupos econômicos em prol do movimento, passaram a atuar por meio de suas fundações privadas ou de suas Organizações Sociais, como Itaú-Social, Faça Parte, Ayrton Senna, Roberto Marinho, Gerdau, Victor Civita, Abril, Bunge, D’Pascoal, Bradesco, Santander, Vale, PREAL, Lemann, entre outros (EVANGELISTA; LEHER, 2012, p. 7).

Interessante notar que as frações da burguesia nacional, sobretudo suas frações industrial e educacional, apesar de concordarem em linhas gerais com a proposta neoliberal da educação, divergiam quanto aos elementos que trariam benefícios particulares a essas mesmas frações. A Confederação Nacional da Indústria (CNI), a propósito de suas reivindicações para a Reforma Universitária que o 
governo Lula começava a propor no início de seu primeiro mandato (2003), expressa seus interesses pelo desenvolvimento das universidades estatais atreladas ao desenvolvimento tecnológico e científico competitivo, vinculando-se a questão da qualidade do ensino e pesquisa articulada com a necessidade de força de trabalho qualificada para o setor produtivo. Para a CNI, não deveria haver o total desmonte das universidades estatais, especialmente porque é lá que se desenvolve a ciência e a técnica no país (RODRIGUES, 2007). No entanto, os investimentos estatais às universidades, devido à "crise fiscal", não se dariam, agora, apenas pelo governo, mas nas parcerias com as empresas, laboratórios particulares, etc.

A posição do capital educacional, especialmente de sua maior entidade na época, Associação Brasileira de Mantenedora do Ensino Superior (ABMES), diverge quanto a questão da qualidade, expressando seus interesses imediatos de expandir ainda mais o ensino superior privado no país, em detrimento do sucateamento ou da secundarização do ensino estatal. Na época, o capital educacional atuava especialmente no ensino superior, chegando a representar $70 \%$ de seus investimentos (RODRIGUES, 2007). Assim, em vistas do anteprojeto da reforma da educação superior do Governo Lula, a ABMES, em conjunto com o Fórum Nacional da Livre-Iniciativa na Educação, direciona um documento chamado Considerações e recomendações sobre a versão preliminar do anteprojeto de lei da reforma da educação superior (FÓRUM, 2005 apud RODRIGUES, 2007). Nesse documento, o capital educacional critica o papel "intervencionista" do Estado na regularização do ensino superior brasileiro, especialmente as centenas de exigências para a abertura de novas faculdades, cursos, etc. Evidencia, também, a necessidade da educação tornar-se plenamente uma mercancia, operada pela iniciativa privada, relegando ao Estado apenas o marco de regulador da educação e não mais com investimentos diretos.

Em síntese, evidenciamos algumas das principais entidades e movimentos que representam os interesses da classe dominante no país quanto a questão da Educação. Veremos a seguir, que eles terão fundamental importância para a consolidação para determinadas escolhas de políticas educacionais orientadas pelo Governo Lula.

As políticas educacionais ${ }^{10}$ no governo Lula giraram em torno do desenvolvimento de um projeto de reforma universitária. É feito, entre o primeiro e o segundo ano de seu mandato, uma comissão interministerial, denominada Grupo de Trabalho Interministerial (GTI) ${ }^{11}$ com objetivo de efetuar um diagnóstico geral das universidades do país (COGGIOLA, 2004). Desse GT, surgem as principais diretrizes das políticas educacionais brasileiras, emergindo o primeiro esboço do anteprojeto da reforma universitária. É interessante constatar que, ao longo das quatro versões desse anteprojeto, cujas modificações se deram pelas centenas de associações, organizações, partidos políticos e representantes da sociedade civil, o governo implementava políticas paralelamente ao ensino superior, através de decretos, projetos de lei, resoluções e portarias. Dessa forma, a verdadeira reforma universitária foi sendo implementada a "conta-gotas", por meios desses decretos e portarias, enquanto, paralelamente, se debatia as diretrizes de um projeto de lei para cristalizar e moldar o que já vinha até então sendo implementado. 
Para fins de nossa proposta, focalizaremos as duas grandes medidas que obtiveram maior impacto e importância nos mandatos de Lula quanto à questão da Educação Superior ${ }^{12}$. Trata-se do Programa Universidade para Todos (ProUni) e o Programa de Apoio a Planos de Reestruturação e Expansão das Universidades Federais (REUNI). O ProUni foi implementado já em seu primeiro mandato, já o REUNI, apresentado como uma das ações do Plano de Desenvolvimento da Educação (PDE), emerge em seu segundo mandato.

\section{ProUni}

O Programa Universidade Para Todos torna-se lei federal em 13 de janeiro de 2005, sob o $\mathrm{n}^{\circ}$ 11.09613. Seu objetivo é a concessão de bolsas de estudos integrais e parciais em cursos de graduação e sequenciais de formação específica em Instituições Privadas de Ensino (IPES).

No período de 1991 a 2004, o número de IPES cresceu 267\% no Brasil, sendo que o número de estudantes matriculados nessas instituições é maior ainda: 311\%, no mesmo período (MICHELOTTO; COELHO; ZAINKO, 2006). Por esse ângulo, tal aumento, sem a devida regulamentação estatal, trouxe um conjunto de problemas que culminaram na deterioração do ensino superior privado em função da não ocupação de vagas durante os governos petistas. Dessa forma, como coloca De Paula (2016, p.133), é nesse contexto que surge o ProUni, “imbuído do discurso de justiça social público-alvo bem definido os estudantes de baixo renda", mas também serviu, fundamentalmente, como resgate do capital educacional no país. Para as IPES, o programa foi um alívio financeiro, pois permitiu remunerar vagas que já eram ociosas e que as instituições já concediam bolsas por conta própria (PINTO, 2009).

O ProUni, assim, atende integralmente as IPES que a ele aderir, garantindo diversas isenções fiscais, tais como a Contribuição Social Sobre o Lucro Líquido; Imposto de Renda de Pessoa Jurídica; Contribuição Social para Financiamento da Seguridade Social e a Contribuição para o Programa de Integração Social (BRASIL/MEC, 2004). De 2005 a 2014 foram gerados um gasto tributário da ordem dos R $\$ 5$ bilhões, com aumento de 352,93\% dos recursos destinados ao programa ao longo desses anos (PLOA, 2014). A ideia de políticas de isenção e incentivos ficais, bem como a transferência direta de verbas para a inciativa privada, é prática comum do Estado brasileiro. Desde o final da década de 60, época dos governos militares, tal prática é incentivada para impulsionar determinados projetos de desenvolvimento nacional (CARVALHO, 2006). Na educação, no entanto, estas medidas fiscais começam de forma tímida nos governos Collor e Cardoso, mas se generaliza nos governos Lula.

Em relação ao Ensino Superior, o mecanismo de renúncia fiscal tornou-se fator central no financiamento do segmento privado. A Lei n. 5.172/66, que instituiu o Código Tributário Nacional, em concordância com a CF/67, determinava a não incidência de impostos sobre a renda, o patrimônio e os serviços dos estabelecimentos de ensino de qualquer natureza. Em outras palavras, as organizações privadas de Ensino Superior gozaram do privilégio, desde a sua criação, de imunidade fiscal, não recolhendo aos cofres públicos a receita tributária devida. [...] Apesar de existirem requisitos restritivos para as entidades educacionais terem acesso à imunidade fiscal, na prática, grande parte usufruiu deste benefício (CARVALHO, 2006, p.982). 
A partir dessa dinâmica de transferência de recursos, o aluno, para conseguir uma bolsa, precisa comprovar sua condição social e/ou qualificação acadêmica/profissional, precisando atender algum requisitos: nota mínima do ENEM (450 pontos); renda familiar, per capita, de até três salários mínimos; ter cursado o Ensino Médio completo em escola Pública, ou o Ensino Médio em escola privada com bolsa integral, ou, ainda, ingressar no sistema de cotas para negros, indígenas e portadores de deficiência. Há a possibilidade, também, do professor da rede pública de Ensino Básico, em exercício, concorrer a vagas em cursos de Pedagogia ou Licenciatura - sem a necessidade de comprovação de renda.

Ao longo dos anos, o ProUni foi se aprimorando e se articulando com outros programas sociais, tais como o programa Fundo de Financiamento Estudantil (FIES) e a utilização das diretrizes do programa de Parcerias Público-Privadas (PPP's).

O programa FIES foi criado em 1999 no governo de FHC14. Se o ProUni oferece bolsas integrais e parciais de 50\% do valor da mensalidade, o FIES concede, diferentemente, o financiamento direto da graduação nas IPES. No governo Lula, a lógica privatista do FIES não foi apenas mantida, como também ampliada. Tal ampliação se deu de modo articulado ao ProUni.

No que diz respeito aos governos do PT, identifica-se que não houve rupturas com a lógica do FIES da época de Cardoso, todavia, deu continuidade em sua operacionalidade, subordinando-se aos interesses do capital. Nessa lógica, foi propalada a Portaria Normativa $n^{\circ}$ 02, de 31 de março de 2008, que articula a distribuição dos recursos do FIES com a concessão das bolsas parciais do ProUni. Assim, os estudantes que obtiverem uma bolsa parcial de $50 \%$ poderão adquirir o restante a partir do FIES (DE PAULA, 2016, p. 115).

Outra política que se articulou com o ProUni foi o Programa de Parcerias Público-Privadas, de escopo mais amplo e que atinge não apenas a educação. As PPP’s foram criadas no final de 2004 (Lei n $^{\circ}$ 11.079), estabelecendo normas para licitação e contratação de empresas privadas a propósito da administração pública. Com a necessidade de gerar superávit primário, as PPP’s foram desenvolvidas para assumir investimentos que o setor público deixara de realizar para efetuar a manutenção do pagamento da dívida que o mercado requer (LOPREATO, 2005). Retirando as atividades reguladoras e legisladoras, as PPP’s são livres para explorar o restante dos serviços públicos, incluindo aí, a saúde, meio ambiente, pesquisa e educação. Trata-se, na verdade, de uma nova modalidade maquiada de privatização de setores e serviços públicos estratégicos.

A partir da efetivação do ProUni, LIT, além do FIES — no qual se trata de outro programa de parceria entre o setor público e o setor privado, essas parcerias na educação superior trouxeram profundas transformações para o setor. Em verdade, implicam uma redefinição do papel do Estado na efetivação do direito à educação, expandindo o setor privado em detrimento do público. No limite, a universidade pública e as Instituições Privadas de Educação Superior (IPES) passam a habitar um sistema único igualando-as no direito de receber investimentos do Estado, portanto, desde que atendam aos requisitos do sistema avaliativo bem como possuam compromisso social. Em síntese, na lógica das PPP's "praticamente" toda a administração pública direta ou indiretamente faz parte de seu abrangente campo (DE PAULA, 2016, p. 11).

Em síntese, o ProUni, propagado pelo governo como uma das maiores e bem-sucedidas políticas educacionais de democratização do ensino superior, maquiando-a enquanto uma política social de 
cunho social-democrata, significou, também, a transferência de uma enorme quantidade de recursos do Estado para o capital educacional. É, sobretudo, uma forma indireta de privatização da educação superior, atendendo, com rigor, aos interesses dos empresários da educação, em detrimento do sucateamento e da corrosão das universidades federais. Passemos agora ao REUNI, outra importante política educacional do Governo Lula direcionado, agora, às instituições estatais, especialmente às universidades federais.

\section{Reuni}

O REUNI é considerado, além de outras determinações, como uma resposta do governo Lula, em seu segundo mandato, às críticas endereçadas ao seu primeiro mandato, tanto ao grande investimento nas IPES quanto à negligência em relação às IFES. O estudo e dados desenvolvidos por Trópia contribui com a dimensão das IFES no primeiro mandato deste governo:

Durante o primeiro mandato do governo Lula, os recursos gastos com as IFES aumentaram de 10.682 milhões de reais, em 2003, para 14.152 milhões, em 2006 - o que representa um aumento de 32,5\%. Ademais, houve um acréscimo nos investimentos nas IFES, que passaram de 51 milhões de reais para 180 milhões, naquele mesmo período. Em 2004, foram investidos 99 milhões de reais e, em 2005, 161 milhões. Embora tenha havido aumento nominal de recursos gastos e de investimentos, os gastos do governo Lula com as IFES ainda deixaram desejar, sobretudo quando comparados ao PIB. Relativamente o ano de 1989, quando 0,97\% do PIB foi investido nas IFES, e ao período FHC - cuja média de investimento foi de $0,64 \%$ do PIB —, o governo Lula investiu em média $0,56 \%$ do PIB durante o primeiro mandato " $0,54 \%$ em 2003; 0,57\% em 2004; 0,53\% em 2005; e 0,62\% em 2006” (TRÓPIA, 2012, p. 368-369).

Com esses dados podemos perceber o aumento nominal dos gastos e investimentos das IFES. No entanto, o valor relativo ao percentual do PIB continuava o mesmo que os dos governos precedentes. Quanto ao número de universidades, foram construídas oito novas instituições, constituindo o total de 53 universidades federais até 2006.

Em seu segundo mandato, Lula lança o Plano de Desenvolvimento da Educação (PDE) ${ }^{15}$ conjugado ao Programa de Aceleração do Crescimento (PAC), sendo o REUNI a sua principal medida quanto às universidades federais. O Programa de Apoio a Planos de Reestruturação e Expansão das Universidades Federais obedeceu às diretrizes, acordadas com o FMI, de ampliar o número de matrícula a 30\% da juventude brasileira de 18 a 24 anos no ensino superior.

O decreto n 6096/2007 implementa o REUNI, que é imediatamente exposto para apreciação das IFES, com “com o objetivo de criar condições para a ampliação do acesso e permanência na educação superior, no nível de graduação, pelo melhor aproveitamento da estrutura física e de recursos humanos existentes nas universidades federais" (Art. $1^{\circ}$ ). Em seu sexto artigo, deixa explícito: “A proposta, se aprovada pelo Ministério da Educação, dará origem a instrumentos próprios, que fixarão os recursos financeiros adicionais destinados à universidade, vinculando os repasses ao cumprimento das etapas". No entanto, como apontam Bessa Léda e Mancebo (2009):

[...] o Parágrafo $3^{\circ}$ do Artigo $3^{\circ}$ claramente condiciona o atendimento das propostas à capacidade orçamentária e operacional do Ministério da Educação. Haverá recurso novo ou apenas uma disputa entre as IFES pelos poucos recursos existentes? De todo modo, o que se pode prever é que, daqui por diante, o repasse de recursos estará vinculado à assinatura de um contrato de metas, a serem atingidas dentro de 
determinados prazos pelas instituições, o que incluirá, além do aumento de vagas, medidas como ampliação ou abertura de cursos noturnos, redução do custo por aluno, flexibilização de currículos, criação de arquiteturas curriculares e ações de combate à evasão, dentre outros mecanismos que levem à expansão do sistema de educação superior (BESSA, LÉDA \& MANCEBO 2009, p. 54).

Assim, há uma vinculação do repasse de novos orçamentos com a necessidade de seguimento de determinadas diretrizes e obediência a determinadas metas, via contrato expedido pelo Ministério da Educação (MEC). Isto significa um grave ferimento na autonomia universitária (já caracterizada por uma frouxidão), estabelecido pelas leis orgânicas das universidades públicas do país. Cria-se uma subordinação burocrática ainda maior nas universidades federais, que deverão agora seguir as diretrizes estabelecidas pelo MEC que, por sua vez, seguem as diretrizes dos órgãos internacionais neoliberais.

Quanto às consequências do REUNI para as universidades, podemos estabelecer fundamentalmente duas. A primeira (já citada) consiste no golpeamento da autonomia universitária. Isso significa dizer que as universidades não possuem mais margem de escolha fora da aplicação da perspectiva estabelecida pelo decreto do REUNI, pois são constrangidas a aderir ao programa graças ao processo de sucateamento que se desenvolveu nos governos neoliberais (de Collor a FHC). A única autonomia que as universidades começaram a ter, sob o REUNI, parafraseando Meek, é a autonomia para livremente se conformar (MEEK apud SGUISSARDI, 2008, p. 25).

A segunda consequência trata-se da questão da indissociabilidade entre ensino-pesquisaextensão, que, no entanto, aparecem dissociadas no decreto do REUNI:

[...] surpreendentemente, a palavra "pesquisa" não aparece uma só vez no Decreto que determina o REUNI; nem no documento de agosto de 2007, que normatiza e detalha o Decreto (intitulado Diretrizes Gerais do Programa de Apoio a Planos de Reestruturação e Expansão das Universidades Federais). [...] Sem meias palavras: a expansão desejada e 'financiada' é só para o ensino, seguindo antigas lições do World Bank (1994), que além de condenarem a predominância das universidades de pesquisa (humboldtianas) - uma realidade que nunca existiu no sistema de educação superior brasileiro - propunham as universidades de ensino (que se ocupariam do ensino ou da formação neoprofissional), mais adequadas aos países com déficit público crônico. Em síntese, o processo de reforma em curso para as IFES implica, por um lado, regredir ou, no mínimo, congelar, o nível científico e técnico da universidade brasileira, sucateandoa e precarizando-a, no geral e, por outro, manter e ampliar os centros de excelência, em determinadas áreas específicas, de acordo com os interesses do capital financeiro, como as relativas a commodities, por exemplo, para o desenvolvimento de tecnologia de cana, de minérios, petróleo, biocombustível, dentre outros (BESSA LÉDA; MANCEBO, 2009, p. 55).

Além disso, o REUNI estabelece a meta de ampliação da taxa de conclusão da graduação em 90\% e o aumento de $100 \%$ do número de discentes por professor, atingindo a média de 18 alunos por docente ${ }^{16}$. Com estas medidas, o que se faz é aumentar ainda mais a precarização das condições de trabalho e o ensino da universidade, já que as verbas destinadas representam um valor aquém das metas estabelecidas. Além destas, há outras medidas, as quais citaremos de forma sumária: criação de bacharelados interdisciplinares (BIs); constituição de professores-equivalentes; alta flexibilização curricular; diminuição do tempo de conclusão dos cursos de graduação; intensificação da utilização de Ensino à Distância $(\mathrm{EaD})$, etc. 
Essas medidas foram recebidas com grande resistência por parte dos professores e estudantes, que denunciaram os malefícios desse programa, apesar de todas as reitorias aceitarem as diretrizes e o contrato do REUNI (BRINGEL, 2009). Ainda no ano de sua implementação, foram ocupadas, por diversas ramificações do movimento estudantil, mais de 14 reitorias das universidades federais simultaneamente. Apesar destas críticas, resistências e ocupações, o REUNI prevaleceu e ditou as diretrizes das universidades federais em todo o mandato Lula e Dilma do Partido dos Trabalhadores.

Possivelmente o REUNI não teria sido tão abnegadamente aceito se o governo não fosse do Partido dos Trabalhadores, com uma figura com tanto lastro de confiança dos setores mais progressistas das universidades como Lula. Também possivelmente o REUNI não teria sido tão unanimidade se não estivesse sendo implementado após um período de grande restrição orçamentária para as universidades federais, como foi o governo Cardoso (CISLAGHI, 2010, p.179).

\section{Consideraçôes Finais}

Em síntese, as políticas educacionais no governo Lula representaram, em seus diversos aspectos, o aprofundamento das medidas neoliberais. O ProUni, apesar de sua expansão, não representou, em nenhum momento, uma guinada na política educacional do período. A transferência direta e indireta de verbas para as instituições privadas continuaram se aprofundando. Mesmo com o aumento nominal de recursos para as IFES, no período de 2002 a 2009, houve um decréscimo do número de matrículas nas instituições públicas em relação às instituições particulares. Em 2002, o total de matrículas concentrada em IES representava 30,2\%. Em 2009 este número cai para 25\% (DE PAULA, 2016). Isto significa que a prioridade do governo Lula era com as instituições privadas, relegando migalhas às IFES e colocando essas políticas como um processo de democratização do ensino público.

A quase totalidade de suas medidas estão em consonância com as cartilhas, programas e cartas das mais diversas entidades e organizações do bloco dominante endereçadas ao governo. A organização Todos Pela Educação, citada anteriormente, produz um plano intitulado Compromisso Todos pela Educação ainda no primeiro governo Lula. Tal plano foi fundamental para a produção do PDE, inclusive foi originado no plano lançado pelo governo chamado Plano de Metas Todos pela Educação, em franca subordinação àquela organização ${ }^{17}$. A tentativa dessas políticas, enfim, é a conformação de uma conciliação entre as mais diversas frações burguesas no interior do capitalismo subordinado brasileiro, com a convergência de um modelo neoliberal.

Sobre essas disputas intraburguesas e a relação com o Governo Lula, Rodrigues (2007) pontua:

Pode-se afirmar, por um lado, que há uma convergência específica entre o capital industrial e o governo em submeter a educação superior brasileira, em particular as universidades públicas, à lógica de produção do valor, particularmente, atrelando a produção do conhecimento às demandas de uma economia competitiva. Por outro lado, também existe uma convergência específica entre os interesses da nova burguesia de serviços educacionais e os do governo, posto que a submissão da universidade pública à racionalidade burguesa e às práticas mercantis acabaria por tornar mais "equânime" a concorrência entre as instituições privadas e públicas. Enfim, há uma convergência geral entre os interesses dos empresários do ensino e dos empresários industriais, que se materializam, mesmo que de forma às vezes conflituosa, nas ações do Poder Executivo, posto que ambas as formas do capital (mercantil educacional e 
industrial) têm na transformação da educação - isto é, uma relação social estabelecida entre homens - em mercadoria (mesmo que especial) - ou seja, uma forma fantasmagórica de relação entre coisas - a mediação para seu interesse mais geral: a valorização do valor pela exploração do trabalho vivo (RODRIGUES 2007, p. 135).

O neoliberalismo neopopulista se conforma como a forma como o Estado se materializou concretamente no contexto brasileiro no início do século XXI nos governos petistas. Evidenciamos aqui apenas as principais determinações das especificidades do neoliberalismo no governo Lula, e as principais medidas colocadas em práticas durante o seu governo, especialmente na questão das políticas educacionais.

\section{Referências}

BARRETO, R. G.; LEHER, R. Do Discurso e das Condicionalidades do Banco Mundial, a educação superior "emerge" terciária. Revista Brasileira de Educação, v.13, p. 423-436, 2008.

BERNARDI, Liane; ROSSI, Alexanre; UCZAK, Lucia. Do movimento Todos pela Educação ao Plano de Ações Articuladas e Guia de Tecnologias: empresários interlocutores e clientes do estado. X ANPED SUL, Florianópolis, outubro de 2014. Disponível em: <http://xanpedsul.faed.udesc.br/arq_pdf/5960.pdf>. Acesso em: 22 jul.2019.

BESSA LÉDA, Denise; MANCEBO Deise. REUNI: heteronomia e precarização da universidade e do trabalho docente. Educação \& Realidade, n. 34, jan.-abr./2009. Disponível em:

<http://www.redalyc.org/articulo.oa?id=317227053004>. Acesso em: 02 set. 2018.

BOITO JR, Armando. A hegemonia neoliberal no governo Lula. Crítica Marxista, Campinas-SP, n. 17, p. 10-36, 2006. Disponível em: < https://www.ifch.unicamp.br/criticamarxista/arquivos.../critica17-Aboito.pdf $>$. Acesso em: 07 jan. 2018.

BRASIL. Ministério da Educação. Portaria Normativa MEC n³9, de 12 de dezembro de 2007. Institui o Programa Nacional de Assistência Estudantil - PANES. Disponível em:

$<$ http://portal.mec.gob.br/arquivos/pdf/portaria_panes.pdf $>$.

BRASIL. Presidência da República. Decreto n 5.025 de 14 de setembro de 2004. Regulamenta as parcerias entre as universidades federais e as fundações de apoio. Brasília, 2004. Disponível em: $<$ http://www.planalto.gov.br>.

BRINGEL, Breno. O Futuro Anterior: continuidades e rupturas nos movimentos estudantis no Brasil. EccoS, São Paulo, v.11, n.11, p. 97-121, jan./jun., 2009.

CARVALHO, C. H. A. Política para o ensino superior no Brasil (1995-2006): ruptura e continuidade nas relações entre público e privado. XXIX Encontro Anual da ANPED, Caxambu, 2006.

CHAGAS, Priscilla; CARVALHO, Cristina Amelia; MARQUESAN, Fabio. Desenvolvimento e dependência no Brasil nas contradições do Programa de Aceleração do Crescimento. Organizações e sociedade. Salvador. Vol. 22, n. 73 (abr./jun. 2015), p. 269-289, 2015. Disponível em: <https://www.lume.ufrgs.br/handle/10183/115080\#>. Acesso em: 10 ago. 2018.

CISLAGHI, J. F. Análise do Reuni: Uma nova expressão da contra-reforma universitária brasileira. (Dissertação de mestrado em Serviço Social, Universidade do Estado do Rio de Janeiro, RJ, Brasil), 2010.

COGGIOLA, Osvaldo. O governo Lula: da esperança à realidade. São Paulo: Xamã, 2004.

COUTINHO, Carlos Nelson. Contra a Corrente: ensaios sobre a democracia e socialismo. São Paulo: Cortez, 2003.

DE PAULA, Alisson Slider do Nascimento. A política de educação superior nos governos petistas: a inflexão da universidade ao capital. 2016. 172 f. Dissertação (Programa de Pós-Graduação em Educação Brasileira). Faculdade de Educação. Universidade Federal do Ceará, Fortaleza, 2016. 
EVANGELISTA, O.; LEHER, R. Todos pela educação e o episódio Costin no MEC. A pedagogia do capital em ação na política educacional brasileira. Trabalho Necessário, v. 10, 2012.

FERREIRA, Emmanoel Lima. O PSTU e as reformas previdenciárias e universitários no governo Lula da Silva. Tese (Doutorado em Sociologia). Fortaleza: PPGS-UFC, 2011.

FILGUEIRAS, L.; PINTO, E. C. Política econômica do Governo Lula e os limites do crescimento. In: GOMES, F. B.; PINTO, E. C. Desordem e Regresso: o período de ajustamento neoliberal no Brasil, 1990-2000. São Paulo: Mandacaru: Hucitec, 2009. p. 252-283.

LEHER, R. A problemática da universidade 25 anos após a crise da dívida. Universidade e Sociedade (Brasília), v. 39, p. 9-15, 2007.

LOPREATO, F. L. C. Finanças Públicas, PPP e Universidade. In: Caderno Adunicamp. Campinas, fev. 2005, p. 6-10.

MAGNOLI, Demétrio. A Bolsa e a vida. Disponível em:

<https://www1.folha.uol.com.br/colunas/demetriomagnoli/2014/10/1534487-a-bolsa-e-a-vida.shtml>. Acesso em: 10 ago. 2018.

MAIA, Lucas. A PEC 55 e o Neoliberalismo Discricionário no Brasil. Revista Despierta. v. 3, n. 3 (2016). Disponível em: <redelp.net/revistas/index.php/rde/article/view/500>. Acesso em: 10 ago. 2018.

MICHELOTTO, Regina Maria; COELHO, Rúbia Helena and ZAINKO, Maria Amélia Sabbag. A política de expansão da educação superior e a proposta de reforma universitária do governo Lula. Educ. rev. [online]. 2006, n.28, pp.179-198. Disponível em:

<http:/ $/$ www.scielo.br/scielo.php?pid=S010440602006000200012\&script=sci_abstract\&tlng=PT>. Acesso em: 02 set. 2018.

ORIO, Mateus Vieira. Lazer e capitalismo. A apropriação do tempo livre pelo capital. Tese (Doutorado em Sociologia) - Programa de Pós-Graduação em Sociologia, Universidade Federal de Goiás, Goiânia, 2018.

PARTIDO DOS TRABALAHDORES. Carta ao povo brasileiro. 2002. Disponível em:

<http://www.iisg.nl/collections/carta_ao_povo_brasileiro.pdf>. Acesso em: 03 ago. 2018.

PINASSI, M. O. O lulismo, os movimentos sociais no Brasil e o lugar social da política. Revista Herramienta, Buenos Aires, 2009.

PINTO, José Marcelino de Rezende. O financiamento da educação no governo Lula. Revista RBPAE, v. 25, n. 2, p. 323-340, mai./ago. 2009. Disponível em:

<http://seer.ufrgs.br/index.php/rbpae/article/view/19500/11324>. Acesso em: 02 set. 2018.

PLOA, SECRETARIA DA RECEITA FEDERAL. Demonstrativo dos Gastos Governamentais Indiretos de Natureza Tributária - (Gastos Tributários) - PLOA 2014. Disponível em:

$<$ https://idg.receita.fazenda.gov.br/dados/receitadata/gastos-tributarios/previsoesploa/arquivos-eimagens/dgt-2014>. Acesso em: 02 set. 2018.

REIS, D. A. O Partido dos Trabalhadores: trajetória, metamorfoses, perspectivas. In: REIS, D. A.; FERREIRA, J. (orgs.). Revolução e democracia (1964-...). Rio de Janeiro: Civilização Brasileira, 2007.

RODRIGUES, J. Os empresários e a educação superior. Campinas: Autores Associados, 2007.

RODRIGUES, Taíla; SALVADOR, Evilasio. As implicações do Programa de Aceleração do Crescimento (PAC) nas Políticas Sociais. Revista SER Social, Brasília, v. 13, n. 28, p. 129-156, jan./jun., 2011. Disponível em: <http://periodicos.unb.br/index.php/SER_Social/article/view/5624/4672>. Acesso em: 10 ago. 2018.

SAVIANI, Dermeval. O Plano de Desenvolvimento da Educação: análise do projeto do MEC. Educ. Soc., Campinas ,v. 28, n. 100, p. 1231-1255, Oct. 2007 . Disponível em:

$<$ http://www.scielo.br/scielo.php?script $=$ sci_arttext\&pid=S0101

73302007000300027\&lng=en\&nrm=iso>. Acesso em: 04 set. 2018.

SGUISSARDI, Valdemar. Modelo de expansão da educação superior no Brasil: predomínio privado/mercantil e desafios para a regulação e a formação universitária. Educ. Soc., Campinas, v. 29, n. 105, p. 991-1022, Dec. 2008. Disponível 
em:<http://www.scielo.br/scielo.php?script=sci_arttext\&pid=S010173302008000400004\&lng=en\&nrm=iso >. Acesso em: 22 jul. 2019.

SHIROMA, E. O.; CAMPOS, R. F.; GARCIA, R. M. C. Conversão das 'almas' pela liturgia da palavra: uma análise do discurso do movimento Todos pela Educação. In: Stephen J. Ball; Jefferson Mainardes. (Org.). Politicas Educacionais: questões e dilemas. 1ed. São Paulo: Cortez, 2011, p. 222-248.

SILVA, Gisele. Capital Portador de Juros e Programas de Transferência de Renda: monetarização das políticas sociais e contrarreforma. Revista de Políticas Públicas Universidade Federal do Maranhão, São Luis, 2009.disponível em:

http://www.periodicoseletronicos.ufma.br/index.php/rppublica/article/view/4766/2781 acesso: 29/09/2019.

TRISTÃO, Ellen. A opção neoliberal do primeiro mandato do governo Lula. Disponível em: <http://periodicos.unb.br/index.php/SER_Social/article/viewFile/5623/4671>. Acesso em: 17 dez. 2017.

TRÓPIA, P. A natureza de classe da política educacional para o ensino superior nos governos Lula (20032010). In: GALVÃO, A.; GALASTRI, L.; SOUZA, J.; AMORIN, E. (Org.). Capitalismo: crises e resistências. São Paulo: Outras Expressão, 2012, v. 1.

VIANA, Nildo. A Constituição das Políticas Públicas. Revista Plurais. UEG. Vol. 1, num. 4, Jan./Dez., 2006. Disponível em:

https://www.academia.edu/5199033/A Constitui $\%$ C3\%A7\% $\%$ C3\%A3o das Pol $\%$ C3\%ADticas P $\%$ C3\% BAblicas acesso em 29/09/2019.

VIANA, Nildo. Representações e valores nas políticas de saúde no Brasil (1990-2012). (Tese de PósDoutorado). São Paulo: Programa de Pós-Graduação em Enfermagem/USP, 2015.

VIANA, Nildo. Vantagens Competitivas, Microreformismo e Imaginário Conveniente - A Integração dos Movimentos Sociais no Capitalismo Contemporâneo. Revista Espaço Livre, v. 12., n. 24, jul./dez., 2017. Disponível em: <http://redelp.net/revistas/index.php/rel/article/view/749/655>. Acesso em: 10 ago. 2018.

\section{Notas}

${ }^{1}$ Doutorando em Sociologia pela Universidade de São Paulo (PPGS/USP). Mestre em Sociologia pela Universidade Federal de Goiás (PPGS/UFG). Orcid: https://orcid.org/0000-0003-3315-1481 Email: teles.gabriel@gmail.com

2 É desse processo que surgem, a partir de tendências já existentes no interior do PT, por exemplo, o Partido Socialista dos Trabalhadores Unificados (PSTU), em 1993; o Partido da Causa Operária (PCO), em 1995; e, enfim, o Partido Socialismo e Liberdade (PSOL), em 2005. Todos eles expressam dissidência de militantes que optaram por sair do Partido dos Trabalhadores e fundar outros partidos.

3 "O processo de inflexão do PT para o neoliberalismo foi gradual, embora tenha decorrido pouco mais de um ano entre o texto Concepção e Diretrizes do Programa do PT para o Brasil, extraído no XII Encontro Nacional do Partido, em dezembro de 2001, e as cartas Ministro da Fazenda, já no Governo Lula, Antonio Palocci ao FMI. O primeiro documento anunciava um governo "democrático-popular" fundado nos eixos social, nacional e democrático, assinalando uma ofensiva contra o mercado, defendendo o crescimento, o emprego e a diminuição da vulnerabilidade externa do Brasil. As cartas ao FMI, tanto a de fevereiro de 2003, quanto a de maio de 2003, ao contrário, anunciavam a continuidade do neoliberalismo de FHC como o verdadeiro programa de governo do PT. No final de 2001, no lançamento de mais uma campanha eleitoral do PT, o programa apresentado poderia ser considerado "social-desenvolvimentista" [...] (TRISTÃO, 2011, p. 8).

$4 \mathrm{O}$ partido, ao longo de seus mandatos, em diversas instâncias (prefeituras, governadores, deputados, vereadores, etc.), já tinha demonstrado que não seria uma ameaça para a burguesia nacional e internacional, o que contribuiu para uma inicial confiança a esse partido conduzir o país com um presidente eleito.

5 "Os setores da sociedade que se aquartelam no Estado formam o bloco dominante. Ele é formado por classes sociais (burguesia, burocracia estatal) e frações de classes e também por forças políticas, organizações e indivíduos. Estas forças políticas, organizações e indivíduos expressam interesses de uma ou outra classe social, mas possuem subdivisões que mostram diferenças ideológicas e modos de agir que são distintos” (VIANA, 2006, p. 15-16).

${ }^{6}$ Devido ao espaço, não evidenciamos algumas delas, como a privatização, direta ou indireta, de diversas empresas estatais, a desarticulação de diversos setores do movimento operário, etc.

7 Antes do governo Lula, o crédito consignado limitava-se aos servidores públicos federais, por legislações regulamentadas desde 1981. Contudo, em 2003, trabalhadores regidos pela CLT (Lei 10.820/2003) e aposentados e pensionistas do INSS (Lei 10.953/2004) também passaram a ter prestações de empréstimo descontados em suas folhas de pagamento (SILVA, 2009). 
8 "As políticas segmentares substituem as políticas universais do Estado integracionista, voltando para segmentos sociais específicos (juventude, negros, mulheres, homossexuais, etc.). É a modalidade neoliberal de políticas estatais" (VIANA, 2017, p 56).

9 Orio (2018, p. 146) nos traz uma oportuna síntese do conceito de mercancia desenvolvido por Viana (2016e): "Fora do âmbito da produção capitalista, nas formas sociais da sociedade capitalista, são produzidos serviços, cultura, entre outras coisas. Estas coisas, para serem vendidas, e consequentemente contribuírem para a reprodução do capital, precisam assumir a "forma" de mercadoria, sendo assim portadoras de valor de troca. Então, estas outras produções sociais, são mercantilizadas, tornam-se mercancias, que não saem diretamente da produção capitalista, não se constituindo em formas de extração de mais-valor, mas são consumadas como forma de apropriação de mais-dinheiro. Assim, as mercancias são elementos mercantilizados da sociedade capitalista que podem ser vendidos fazendo com que seu vendedor se aproprie de parte do mais-valor distribuído na sociedade na forma de dinheiro".

10 Evidentemente que nosso focará será o ensino superior. Assim, quando falarmos em "políticas educacionais", estamos nos referindo às políticas estatais específicas para o ensino superior brasileiro.

11 Tal GT foi formado por seis ministérios: Educação; Casa Civil, Planejamento, Fazenda, Ciência e Tecnologia e Secretaria Geral da Presidência, objetiva em última análise, elaborar idéias para a reforma universitária.

12 Entre outras medidas importantes, podemos citar a implantação do Sistema Nacional de Avaliação da Educação Superior (SINAES); a outorgação da Lei de Inovação Tecnológico; a reestruturação do Exame Nacional do Ensino Médio (ENEM); e a rearticulação do Fundo de Financiamento Estudantil (FIES).

13 No entanto, o seu surgimento se dá já em 2004, a partir do projeto de lei 3.562/2004 encaminhado ao Congresso Nacional. Segundo De Paula (2016, p. 112) "O ProUni deveria ter sido lançado em 17 de abril de 2003, mas Lula da Silva optou por adiar seu lançamento. Conforme o jornal Folha de São Paulo (2004), o ProUni foi alvo de ataques por reitores das IFES, bem como de representantes de associações de entidades privadas de ensino superior, estes últimos empreenderam uma crítica acerca do percentual de vagas a serem abertas, em contrapartida exigiram como moeda de troca a isenção do imposto de renda e de mais três tributos para os estabelecimentos com fins lucrativos".

14 Tal programa substituiu o antigo Programa de Crédito Educativo (PCE) que vigorava desde 1976 no Brasil.

15 Para mais informações e uma análise sobre o PDE cf. SAVIANI, 2007.

16 " [...] como meta global a elevação gradual da taxa de conclusão média dos cursos de graduação presencial para noventa por cento e da relação de alunos de graduação em cursos presenciais por professores para dezoito ao final de cinco anos, contando do início de cada plano" (BRASIL, 2007).

17 [...] como o próprio nome já diz, é um plano que prevê o desenvolvimento da educação no Brasil com o objetivo de investir na educação básica através de projetos que envolvam toda comunidade escolar por meio de iniciativas que garantam o sucesso e a permanência com qualidade do aluno na escola. Vale lembrar que o PDE assumiu todas as metas do Movimento, certificando a sujeição da política educacional ao consenso construído pelos empresários brasileiros (BERNARDI; ROSSI; UCZAK, 2014, p. 8).

Recebido em: 2019-07-23

Aceito em: 20.08.2019 